\title{
Livestock Price Formation in Suri Pastoral Communities in Bench Maji Zone, Southwest Ethiopia: Hedonic Property Value Approach
}

\author{
Getahun Kassa ${ }^{*}$, Dessalegn Anshiso, Tegegn Fantahun \\ Mizan-Tepi University, College of Agriculture and Natural Resources, Mizan-Aman, Ethiopia \\ Email address: \\ zgetah@gmail.com (G. Kassa) \\ ${ }^{*}$ Corresponding author

\section{To cite this article:} \\ Getahun Kassa, Dessalegn Anshiso,Tegegn Fantahun. Livestock Price Formation in Suri Pastoral Communities in Bench Maji Zone, \\ Southwest Ethiopia: Hedonic Property Value Approach. International Journal of Agricultural Economics. Vol. 2, No. 4, 2017 , pp. 90-95. \\ doi: $10.11648 /$ j.ijae.20170204.11
}

Received: March 27, 2017; Accepted: April 10, 2017; Published: June 7, 2017

\begin{abstract}
Livestock are non-marketed assets which are used to enhance social status in Suri pastoral communities. The lack of access to formal or informal market for livestock, livestock products and by-products in the area forced the Suris to barter livestock with other physical properties in times of family emergencies and food shortage. This study, therefore, aimed at assessing how livestock price was formed in a bartering economy in Surma pastoralist district. Primary data were collected through key informant interview and structured questionnaire. A total of 100 pastoralists were selected by using simple random sampling technique. Data were analyzed using hedonic property value (HPV) approach and multiple linear regression analysis. The result revealed that livestock rearing provide multiple benefits to Suris in terms of enhancing wealth and social status, dispute settlement, source of diet and bride payment. The absence of market place and periodic market date in the area made Suris to barter cattle forbarn of maize, Kalashnikovs, goats and gold mine. However, physical characteristics like age and body condition of ox/bull; and external factors like season and market location affected cattle price. Therefore, attention has to be given to the factors affecting cattle price to improve the benefits of the pastoralists.
\end{abstract}

Keywords: Pastoralists, Hedonic Property Value Approach, Price Formation, Barter Economy

\section{Background}

Pastoralism, the use of extensive grazing in rangelands for livestock production, is one of the key production systems in the world's dry lands [1]. The World Initiative for Sustainable Pastoralism (WISP) defines pastoralism as any predominantly livestock-based production system that is mainly extensive in nature and uses some form of mobility of livestock [2]. In pastoral systems livestock production is the mainstay of people's livelihood. Large livestock holdings including sheep, goats, cattle, and sometimes camels comprise the bulk of their limited wealth and are an integral part of their socio-cultural life [3].

Pastoralism goes beyond the simple form of traditional herding whose economic benefits would be limited to only the resources derived from the sale of meat, milk and byproducts from herding (leather, horns) [4]. Pastoralism is not simply a commercial operation, but has deep social, political and cultural roots [5]. Herd size is often directly correlated to wealth and social status in the pastoral societies [3]. By continuing to manage indigenous livestock breeds, pastoralists maintain not only genetic diversity but also important indigenous knowledge regarding the health, management and reproduction of livestock [6].

Pastoralism has been shown to be an efficient means of production in the arid areas of Africa and if enhanced, it can be used to meet the growing demand for livestock and livestock products while improving the livelihoods of the pastoralists [3]. However, pastoral societies are currently facing many challenges in the face of population growth and urbanization, changes in land use, commoditization of activities, monetarization of trade, globalization and the multiplication of conflicts [4]. They lack vital infrastructure in the form of accessible roads, electricity and telecommunications, leaving them increasingly isolated [3].

In most pastoralist communities livestock rearing is 
considered as a means of achieving high social status. As a result, livestock are non-marketed assets for pastoralists. The benefit pastoralists derive from non-marketed, or nonconsumptive, values may clearly lower the marginal utility of the livestock off take relatively to livestock inventory and hence, result in larger herds and higher grazing pressure compared to situations when such non-marketed values are absent. Simply, income is generated in the form of capital gains, not from the sale of livestock [7]. However, pastoralists, besides using livestock as sources of food and as a form of saving and wealth, sell animals at times of cash needs to purchase food and other necessities [8]. When pastoralists sell animals they are simply monetizing capital gains for two principal reasons: to meet immediate cash needs; andto sell high value assets with low growth potential (slaughter bulls), and use the proceeds to purchase high value assets with high growth potential (heifers) [8].

The high socio-cultural value associated with livestock made livestock as non-marketable assets used to enhance wealth and social status in Suris' pastoral communities. There is no formal or informal market for exchanging livestock, livestock products and by-products in the area. Consequently, livestock bartered with other physical properties.It is, therefore, important to assess how livestock price being formed in the area by using surrogate market approach. A focus on livestock price formationisimportant as pricesarecentral measure for livestock market performance and efficiency.

\section{Materials and Methods}

\subsection{Description of the Study Area}

This study was conducted in Surma pastoralist districtin Bench Maji Zone, SNNP Region. The district is remote, sparsely populated, and food secure. The district is bordered to the south and west by Sudan, to the north by the Acobo River and Bero district, and to the east by Maji district. Grazing land is communal and relatively plentiful. The district has many permanent rivers and seasonal streams. Households that are settled in these areas do not have to move with their livestock in search of water in the dry season. Households live together and share resources in common. They have significant livestock numbers per household. The types of livestock reared in the zone are cattle and goats [9]. Suri livelihoods consist of herding livestock (cattle, goats, and sheep), shifting cultivation, and hunting and gathering. Since the 1980s, Suri have traded alluvial gold with highland traders for cash income, often used for cattle purchases [10].

The Suri environment is a hot savannah landscape between 900 and 1500 meters altitude, mostly plains, hills and some scattered mountains reaching above $2000 \mathrm{~m}$. It is characterized by unpredictable seasonal rainfall and the frequent threat of food shortage or local famine and of cattle diseases. Cattle camps (all-male population) are in the plains at lower altitude [11]. Livestock raiding of neighboring groups, such as Nyangatom, Toposa and to a lesser extent Murle and Dizi, is a common practice and is rooted in the past [12].

Based on the 2007 Census conducted by the CSA, this district has a total population of 24,598 , of whom 11,794 are men and 12,804 women; 914 or $3.72 \%$ of its population are urban dwellers. The majority of the inhabitants practiced traditional beliefs, with $96.25 \%$ of the population reporting that belief, $1.63 \%$ practiced Ethiopian Orthodox Christianity, and $1.59 \%$ was Protestants. The educational enrolment rate of the district is $16.25 \%$ male and 3.94 female from the total population [13].

\subsection{Source of Data}

For the purpose of this study, both primary and secondary data were collected. Primary data were collected using structured questionnaire and key informant interview. Secondary data were collected from pastoral development project coordination office in the district.

\subsection{Sample Size and Sampling Techniques}

Three stage sampling techniques were employed to select pastoralists. In the first stage, Surma district was selected based on pastoral livestockproduction system. In the second stage, three kebelesnamely Tulgit, Koka and Majakebeles were selected based on accessibility to road. In the third stage, 100 pastoralists were selected by using simple random sampling technique.

\subsection{Method of Data Analysis}

Three types of analysis techniques, namely descriptive statistics tools (like mean, standard deviation, percentage, and table), Hedonic Property value Approach and multiple linear regression analysis were employed. Data were analyzed by using SPSS version 21 .

In the absence of a market, information can be drawn from related marketed goods (surrogate markets) to determine the use value of the non-marketed goods [14]. For this analysis, the surrogate market technique, i.e., the hedonic pricing method was employed to analyze the pricing of livestock. The fundamental theory of the hedonic price model explains the price $(P)$ of a commodity as a function of its characteristic [15]. The underlying hypothesis is that products have utilitybearing attributes and the values of those attributes contribute to the price of the product [16]. The model's assumption is that a product is composed of a variety of specific attributes that consumers value independently. Thus, the observed price of a good is a composite of the implicit values of the product's attributes.

The general implicit form of the model can be presented as follows:

$$
\mathrm{P}=\mathrm{f}\left(\mathrm{X}_{1}, \mathrm{X}_{2}, \mathrm{X}_{3}---------\mathrm{X}_{\mathrm{n}}\right)
$$

Where $\mathrm{P}$ is the market price of live cattle and $\mathrm{x} 1, \mathrm{x} 2, \ldots, \mathrm{xn}$ are the various price determinants.Physical factors such as age, sex of cattle, body condition, season, and market 
location were considered to affect cattle price. In addition, external aspects such as seasonality and market locationwere also explained the differences in market prices.

In order to eliminate day-to-day variation in the cattle prices, the model was transformed to log function. The model transformation allowed to measuring the coefficients as elasticity. Thus, the marginal implicit price for cattle was transformed to $\log$ function as $\partial \mathrm{P} / \partial \mathrm{q}$.

Where $\mathrm{P}$ is the observed price of the product,

$\mathrm{q}$ is a set of attributes affecting cattle price.

\section{Result and Discussion}

\subsection{Purpose of Livestock Rearing}

Livestock are a form of productive capital in Suri pastoral communities by providing a stream of social and economic benefits. Based on social, cultural and economic significance to the Suri pastoralists, livestock are important part of Suris' day to day lives. Most often livestock are used for ceremonial purposes, milk, cow blood ceremony, and in times of emergency, for trade and sale [10]. The socio-cultural and economic benefits Suris' derive from livestock rearing are listed below.

(A) Indicators of wealth

Cattle are enormously important to the Suri. They bring status; when two Suri meet they will ask each other how many cows they have. Key informants indicated that livestock in the Suri pastoral communities are the principal indicators of wealth. Suris measure the wealth of a family by the number of animals owned. Wealth is categorized in to three categories such as rich, medium and poor based on the number of cattle a family own. On this basis, those having a total number of cattle ranging from 200-300 are considered as the wealthiest in the community, whereasthose having cattle ranging from 20-30 are categorized as medium, and those pastoralists having cattle population less than 5 are considered as poor.

(B) Indicators of social status and social prestige

On the basis of number of cattle, Suris' classify social status in to two as 'highly respected person' and 'ordinary person'. Thus, the one who own a total number of cattle ranging from 200-300 enjoy the highest social stature in Suri pastoral communities; whereas those having cattle numbers less than 30 are considered enjoy low social stature as 'ordinary'.In "Ref. [11]" it is stated that Suris heavily invest in augmenting their personal cattle herd and build themselves social status in expanding it.

In line with Suris' strong interaction with cattle, key informants also reported that a Suri man uniquely gives intense care and affection to a "song bull." Every man has his own song bull which is used as a revelation of pride and social prestige. When the "song bull" dies, mourning rituals will be performed by family members. Consistent with this, in "Ref. [17]" it was reported that the Suri sing songs in praise of their cattle, and mourn them when they die.

(C) Source of food
The Suri pastoral communities do not rear cattleprimarily with the intent of consuming meat and milk products. Very rarely are cattle eaten - and only in large ceremonies [10]. Thus, slaughtering occurs only in big ceremonies or when the cow/ox dies or becomes physically weak due to old age. Regarding consumption of milk, it is usually consumed at the farm gate. Key informants indicated that there is a myth regarding milk consumption in to believing that milk consumption by a sexual active person in the $1^{\text {st }}$ week of sexual intercourse has a catastrophiceffect on the cow in the form of infertility.

On the other hand, blood isthe primarydietthat is usually consumed by the Suris.An animal can be bled once a month, from the jugular. Bleeding a cow is more efficient than slaughtering it for meat.

(D) Bride wealth (Dowry)

According to key informants, cattle ownership in the Suri pastoral communities is useful means of attracting girls for marriage. Bride wealth is given and taken as part of tradition, and no marriage takes place without the payment of bride wealth. A bridegroom pays of 15-20 cattle to the bride's parents. The dowry mustconsistof different age and sex groups of cattle. The bride will be named after an ox with excellent body size allotted to her parents as bride wealth.In line with this finding, it was noted that the largest single allocation of livestock that a male herder is likely to make in a lifetime is for bride wealth at marriage, which exceeds 15 cattle and numerous small stocks in parts of East African Pastoralists [18]. However, bride wealth will be refunded to the bridegroom if the bride fails to give birth to a baby boy in later years of their marriage.

In addition, any forced sexual violence committed on a Suri girl resultingin unwanted pregnancy will only be settled with a bride wealth of 15-20 cattle to her parents. However, compensation payment is conditional up on the sex of the child. Half of the bride wealth will be refunded if the woman gives a birth to a baby girl.

(E) Goats as a start-up capital

Goats in the Suri pastoral communities are considered as an initial capital which will be stored and accumulated to start up cattle rearing. Goats deliver every service to the poor equivalent to which a cow delivers to its herder. As a result, goats are considered as 'poor man's cow'. In line with this, in "Ref. [11]" it was stated that Suri woman often sell grain and beer to buy goats and then later convert a number of them into cattle.

(F) Sheep fordisputesettlements

According to key informants, In the Suri pastoral communities, sheep rearing is very uncommon. Sheep are not preferable source of nutrition (food) like cattle and goats for Suris. However, sheep are used for settlement for tribal and ethnic conflict in the area. In line with this, in "Ref. [11]" it was noted that cattle used as compensation after conflict so that they make conflict resolution possible.

(G) Skin and Hide

After processed for a certain days, mattress would be prepared from cattle skin. Hide from goats are useful as baby 
carriage and made traditional/cultural clothes to be worn in special occasions. The dried cattle-skins are the mats on which people sleep, and a skin of a favorite animal or clan emblem animal is the one on which people sit when negotiating marriages or homicide compensations [11].

\subsection{Livestock Valuation by Using Hedonic Property Value}

In Surmapastoralist district, market for livestock does not exist. The Suri have a basic subsistence and barter economy. There was no specific market place and/or periodic market dates where livestock, livestock products and by-products exchanged, particularly among pastoralists. Thus, pastoralists use system of bartering instead of money.

1) Bartering of heifer for bull

Key informants indicated that a bull was bartered for 2 heifers. However, the number of heifers to be bartered may increase from 2 to 3 with an excellent body size of a bull. Based on this fact, the price of heifer was estimated to be 3,000 ETB in nearby market.

2) Calves plus a lump sum of money

As to key informants, a bull was bartered for two calves and a certain lump-sum of money ranging from $1000-2000$ Ethiopian birr contingent upon cattle body size. Pastoralists'passion for owning large number of cattle made this offer appealing to the herders/ pastoralists. Since, the price of a calf was estimated to be in the range of $1700-$ 2000 , the value of a bull could be estimated to be in the range of 3,400 - to 6,000 ETB.

3) Heifer for a barn of maize

For theSuri pastoralist, maize is the main source of food.One means of cattle acquisition in the area for poor was bartering for barn full ofmaize. Simply, engagement in maize cultivation considered as one means of cattle acquisition for poor farmers. Key informants indicated that a barn (traditional storage) of maize was bartered for a heifer. Thus, in this exchange, one party meets family members' and his own food demand, whereas the other party meets his demand for cattle acquisition. The traditional storage in the area assumed to have 8 quintals of maize. Since the price per kilogram of maize in the nearby market was 4 Ethiopian birr,then, the value of heifer was estimated to be 3,200 ETB.

4) Bartering Kalashnikovs for cattle

The tribe is used to constant conflict with neighboring tribes for land and cattle. Kalashnikovs was the most important fire arm to protect their livestock and themselves from any external attack byneighboringtribes. Thus, in the area 1 Kalashnikovs was bartered for 7 cattle ( 2 oxen, 2 cows, 3 heifers). In the black market, Kalashnikovs was sold for 20,000 ETB. Thus, the value of seven cattle based on their age, sex and body size was estimated to be 20,000 ETB.

5) Bull for a piece of gold

To meet their immediate financial needs, pastoralists travel to nearby gold mining cites where they can change meat for a piece of gold-mine. This is just like retailing meat products for gold miners.According to key informants, the value of an ox was estimated to be 10,000 ETB.

6) Bartering goats for heifer
In the Suri pastoral communities, goats were among the main components of livestock. Particularly for the poor, acquisition of heifer could be challenging in the absence of goat rearing. Pastoralists commonly bartered heifer for 7 goats. Since the price of goat in nearby markets were 500 $\mathrm{ETB} /$ head, the value of heifer could be estimated to be 3,500 ETB.

\subsection{Reasons for Cattle Trading}

(A) To address health problem in pastoralist family members

One condition forcing pastoral communities to sale cattle is when there is an emergency in the pastoralist's family member to be met urgently. During emergencies, a pastoralist travels more than $40 \mathrm{kms}$ on foot to non-pastoralist areas to get access to cash which will also be instrumental to cover for medical costs for sick family member/s. After covering for medical cost, the remaining portion of the money will be re-invested to replace the sold live animal.

(B)To meet seasonal food shortage

In the study area, pastoralists suffer the problem of food shortage from February to July every year. During this period of shock and food shortage, in order to meet family members immediate food demand a pastoralist would travel long distances to sell cattle. The money received from the sale of cattle will be used to purchase food items mainly maize. The remaining amount of money from the sale of an ox/bull will be distributed to family members because ownership is communal.

\subsection{Determinants of Cattle Price}

The multiple linear regression analysis was carried out to identify the factors influencing cattle price formation in Suri pastoralist communities. The $\mathrm{F}$ test shows that the model is significant at less or equal to $0.000 \%$ probability level. The $\mathrm{R}^{2}$ value of 0.37 indicates the explanatory power of the model. Thus, $37 \%$ of the variation in the dependent variable was explained by the regression. Physical and environmental characteristics affected formation of cattle price in the study area. Thus, out of five variables, explanatory variables such as age of ox/bull, season, body size, and market location significantly affected cattle price in the study area.

Table 1. Determinants of cattle price.

\begin{tabular}{lllll}
\hline Variables & Coefficient & Std. error & t-statistics & Significance \\
\hline Constant & 3812.028 & 4515.882 & .844 & 0.402 \\
Age of cattle & 2451.435 & 882.880 & 2.777 & $0.008^{* * *}$ \\
Sex of cattle & 1702.171 & 2326.026 & .732 & 0.467 \\
Season & 2769.562 & 1323.203 & 2.093 & $0.041^{* *}$ \\
Body size & 2618.806 & 1109.170 & 2.361 & $0.022^{* *}$ \\
Market location & -1540.123 & 649.270 & -2.372 & $0.021^{* *}$ \\
\hline
\end{tabular}

$* *$, and $* * *$ refers to significance at less than $5 \%$, and $1 \%$ probability levels, Dependent Variable: Value (Price * quantity sold), R-square $=0.423$, Adjusted R-Square $=0.37$, F-value $=7.922$. 
As an important variable, age of cattle was found to be positively and significantly associated with cattle price at less than $1 \%$ significance level. This implies those pastoralists who supplied cattle within the age range of medium to old tended to be offered better price in the market. In line with this finding, "Ref. [19]" indicated that prices are highest for matured animals for all the three types of animals (sheep, goat, and cattle) relative to the immature and young.

In this study, cattle price and seasonality were positively and significantly associated at less than 5\% significance level. The positive association between seasonality and cattle price indicates that selling cattle in festive-season is more likely to enable pastoralists earn better price. In line with this finding, it was revealed that the variable representing religious festivals has significant positive coefficient implying that cattle are likely to be sold at significant price premiums during festivals [20].

Another important variable that affects cattle price was body size. This variable was positively and significantly associated with cattle price. The positive association indicates that a medium or excellent body size is important to receive good offer in the cattle market. In line with this finding,"Ref. [19]" indicated that buyers paid significantly higher premium for shoat and cattle with excellent body condition.

Market location was found to be negatively and significantly associated with cattle price. The absence of market place and market date in the area forced pastoralists to travel long distance to neighboring areas to sale their livestock. The negative association between cattle price and market location implies in the absence of market information pastoralists travel to different areas in search of market opportunities. In line with this finding, it was found that traders spent relatively lower prices if they operate and sourced the livestock from larger number of markets [19]. This may show that as the number of source markets for livestock increases, the average price is significantly reduced [Ibid]. Another report also noted that herders often arrive in market towns after long treks and are vulnerable to low prices [21].

\section{Conclusion and Recommendation}

The finding of this research revealed that livestock production plays a significant role in Suri pastoral communities. Livestock serve as indicators of wealth and social status, source of blood, bride payment, and dispute settlement. However, the lack of market in the area contributed for the creation of bartering economy. Consequently, cattle bartered for other physical properties (assets) like barn of maize, KALASHINKOVS, goats, and a piece of gold mine. Though the high socio-cultural value associated with livestock made livestock non-marketable assets to theSuris, livestock were smuggled out to neighboring districts for sale to meet family emergencies like covering for health cost, and during a period of seasonal food shortage. However, the price offered to the pastoralist affected by physical factors like age and body size, and external factors like seasonality and market location. Therefore, attention has to be given to the factors affecting livestock price so as to improve the benefits of the pastoralists.

\section{Acknowledgment}

We thank Mizan-Tepi University for funding this research. We also are highly indebted to Mr. Bardula.

\section{References}

[1] Blench, R. (2001). 'You can't go home again' Pastoralism in the new millennium. 2001.Institutional Research Fellow, Overseas Development Institute, London, UK.

[2] The World Initiative for Sustainable Pastoralism (WISP). (2006). Global Review of theEconomics of Pastoralism.

[3] Ouma, E., Abdulai, A., and Drucker, A. (nd). Pastoralists Preferences for Cattle Traits:Letting them be heard. Paper Contribution for the Conference on Pastoralism and PovertyReduction in East Africa: A Policy Research Conference to be held in June 27-28,Nairobi, Kenya.

[4] Food Sovereignty Brief. (2012). Pastoralism in Sub-Saharan Africa: Know its Advantages, Understand its Challenges, Act for its Sustainability. No. 5. May 2012.

[5] The Economist Intelligence Unit (EIU). (nd). The Horn of Africa Livestock Market System:Lessons from Elsewhere. A report by The Economist Intelligence Unit.

[6] Convention on Biological Diversity (CBD). (2010). Pastoralism, Nature Conservation and Development. A Good Practice Guide.

[7] USAID. (2016). Karamoja Livestock Market Assessment Report. USAIDEast AfricaResilience Learning Project, January 2016.

[8] Jabbar, M. A., and Gezahegn, A. (2003). Livestock Marketing, Food Security and RelatedIssuesin Ethiopia.

[9] SNNPR (south nation's nationalities peoples region) Livelihood Profile, (2005). Surma Agro-Pastoral Livelihood Zone.

[10] The Oakland Institute, (2014). Engineering Ethnic Conflict. The Toll of Ethiopia'sPlantation Development on The Suri People.

[11] Abbink, J. (2003). Love and death of cattle: The paradox in Suri attitudes toward livestock,Ethnos, 68: 3, 341-364.

[12] Abbink, J. (2000b). Tourism and its Discontents: Suri-Tourist Encounters in SouthernEthiopia. Social Anthropology, 8(1):1-17.

[13] CSA (Central Statistical Authority), (2007). Statistical census. Addis Ababa, Ethiopia.

[14] Polasub, W. (2008). Economic Valuation Based on Surrogate Market. Regional Training Workshop on "The Economic Valuation of the Goods and Services of Coastal Habitats", March 24-28, 2008, Samut Songkram, Thailand.

[15] Rosen, S. (1974), "Hedonic Prices and Implicit Markets: Product Differentiation in PureCompetition." Journal of Political Economy. 
[16] Williams, T. O., Okike, I., and Spycher, B. (2006). A Hedonic Analysis of Cattle Prices inthe Central Corridor of West Africa: Implications for Production and Marketing Decisions. Contributed paper prepared for presentation at the International Association of Agricultural Economists Conference, Gold Coast, Australia, August 12-18, 2006.

[17] BBC, (2014). BBC Documentary.

[18] Bailey, D. V., Barrett, C. B., Little, P. D., and Chabari, F. (1999). Livestock Markets andRisk Management among East African Pastoralists: A Review and Research Agenda.

[19] Hailemariam, T., Getachew, L., Dawit, A., and Asfaw, N.
(2009). Determinants of Livestock Prices in Ethiopian Pastoral Livestock Markets: Implications for Pastoral Marketing Strategies. Contributed Paper prepared for presentation at the International Association of Agricultural Economists Conference, Beijing, China, August 16-22, 2009.

[20] Teressa, A. (2006).Determinants of Market Prices of Cattle in Eastern Ethiopia.Contributedpaper prepared for presentation at the International Association ofAgriculturalEconomists Conference, Gold Coast, Australia, August 12-18, 2006. mmunication Initiative 2007.

[21] UN OCHA Pastoralist Communication Initiative (UN OCHA PCI). (2007). The Future of Pastoralism in Ethiopia.4Ttht. 